\title{
Risk factors for mortality and failure of conservative treatment after aortic type $B$ dissection
}

\author{
Jochen Grommes, MD, ${ }^{\mathrm{a}}$ Andreas Greiner, MD, ${ }^{\mathrm{a}}$ Bianca Bendermacher, MD, ${ }^{\mathrm{c}, \mathrm{e}}$ Max Erlmeier, MD, \\ Andreas Frech, MD, ${ }^{\mathrm{b}}$ Perrine Belau, MD, ${ }^{\mathrm{a}}$ Lieven N. Kennes, PhD, ${ }^{\mathrm{d}}$ Gustav Fraedrich, MD, ${ }^{\mathrm{b}}$ \\ Geert Wilhelm Schurink, MD, PhD, ${ }^{\mathrm{c}}$ Michael J. Jacobs, MD, PhD, ${ }^{\mathrm{a}, \mathrm{c}}$ and Josef Klocker, $\mathrm{MD}^{\mathrm{b}}$
}

\begin{abstract}
Background: Despite medical treatment, one third of patients with uncomplicated type B aortic dissections experience severe late complications. The aim of this study was to identify patients at high risk of mortality during follow-up.
\end{abstract}

\begin{abstract}
Methods: A total of 183 patients with acute Stanford type B dissection were treated in one of the university hospitals (Aachen [Germany], Maastricht [The Netherlands], and Innsbruck [Austria]) between 1997 and 2010. Records indicated that 120 patients were treated conservatively. Of these patients, 16 were lost to follow-up. The maximum diameter, extent of the dissection, and patency of the side branches were determined from computed tomography angiography data. Survival and treatment failure were analyzed by univariate and multivariate Cox regression analysis. The univariate analysis investigated the influence of aortic diameter $(\geq 41$ vs $<41 \mathrm{~mm}$ ) on survival, and the multivariate analysis investigated the influence of aortic diameter, age, sex, and surgery on survival.
\end{abstract}

Results: During the follow-up period, the initial treatment was converted to surgical treatment in 21 patients $(20.2 \%)$. Sixteen of the 104 patients $(15.4 \%)$ died after a mean of $845.5 \pm 805.9$ days. The mean maximum aortic transversal diameter at admission was $41.2 \pm 8.7 \mathrm{~mm}$. The multivariate analysis identified aortic diameter $(P=.004$; hazard ratio, 1.07) and age $(P=.038$; hazard ratio, 1.05$)$ as risk factors that significantly reduce survival.

Conclusions: Our study revealed both early aortic dilatation and older age as risk factors for increased mortality after conservative treatment of type B dissection. (J Thorac Cardiovasc Surg 2014;148:2155-60)

\section{Supplemental material is available online.}

Despite medical treatment, one third of patients with type B aortic dissection have life-threatening complications, including death, rupture, increasing aortic diameter, and visceral or lower-limb ischemia, over the course of 5 years. ${ }^{1,2}$ Data from the International Registry of Aortic Dissection (IRAD) reveal high mortality, with 1 in 4 patients dying within 3 years after acute type B dissection. After discharge, an estimated $31 \%$ to $66 \%$ of deaths are caused

\footnotetext{
From the European Vascular Center Aachen-Maastricht, ${ }^{\text {a }}$ University Hospital RWTH, Aachen, Germany; Department of Vascular Surgery, ${ }^{\mathrm{b}}$ Medical University, Innsbruck, Austria; European Vascular Center Aachen-Maastricht, ${ }^{\mathrm{c}}$ Medical University, Maastricht, The Netherlands; Department of Medical Statistics, ${ }^{\mathrm{d}}$ University Hospital RWTH, Aachen, Germany; and Division of Vascular Surgery, ${ }^{\mathrm{e}}$ Catharina Hospital, Eindhoven, The Netherlands.

Disclosures: Authors have nothing to disclose with regard to commercial support.

Drs J.G. and A.G. contributed equally to this work.

Received for publication Nov 11, 2013; revisions received March 25, 2014; accepted for publication March 28, 2014; available ahead of print May 3, 2014.

Address for reprints: Jochen Grommes, MD, European Vascular Center

Aachen-Maastricht, University Hospital RWTH Aachen, Pauwelsstraße 30,

52074 Aachen, Germany (E-mail: jgrommes@ukaachen.de).

$0022-5223 / \$ 36.00$

Copyright (C) 2014 by The American Association for Thoracic Surgery

http://dx.doi.org/10.1016/j.jtcvs.2014.03.053
}

by dissection-associated complications, such as rupture or perioperative mortality from aortic repairs. ${ }^{3-8}$

The current criteria for primary surgical or endovascular repair of type $B$ dissections include primarily lifethreatening scenarios, such as rupture, malperfusion syndrome, progression of the dissection, enlarging aneurysms, and an inability to control blood pressure or symptoms. ${ }^{7,9-12}$ The theoretic aim for thoracic endovascular aortic repair (TEVAR) in acute type B dissection is to remodel the architecture of the aortic wall by covering the proximal entry tear of the dissection and reexpanding the true lumen, thereby excluding the false lumen. Prophylactic TEVAR in uncomplicated type B dissections should prevent complications, particularly aneurysm enlargement. The first randomized study of elective stent-graft placement in survivors of uncomplicated type B aortic dissection, the INvestigation of STEnt grafts in patients with type B Aortic Dissections (INSTEAD) trial, did not reveal a difference in the 2-year cumulative survival between optimal medical therapy and TEVAR. ${ }^{2}$ In contrast to these results after 2 years, the long-term results displayed an improved survival after TEVAR. ${ }^{13}$ However, conservative treatment is still recommended for uncomplicated type B aortic dissection. ${ }^{11,14}$

However, the current therapeutic strategy of waiting until the criteria for surgical or endovascular repair are met 


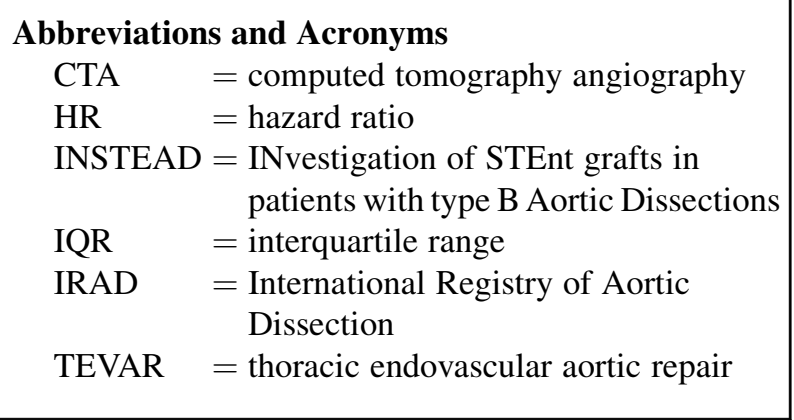

seems to endanger some patients. In particular, patients with evolving transversal aortic enlargement are confronted with perioperative mortality and morbidity from subsequent aortic repairs or jeopardized by a substantial risk of rupture. ${ }^{3,5,7,15}$ The aim of this study was to analyze the course of uncomplicated, conservatively treated type B dissections to identify patients with increased mortality during follow-up.

\section{METHODS}

\section{Patients and Treatment}

Between January 1997 and February 2010, 183 patients with an acute Stanford type B dissection as confirmed by multidetector computed tomography angiography (CTA) were admitted to 1 of 3 university hospitals in 3 specific centers. Among these patients, 63 (34\%) had evidence of complications, such as rupture, excessive aortic enlargement, or visceral, renal, or extremity ischemia, and were referred for surgical or endovascular repair. Patients with uncomplicated type B dissection ( $\mathrm{n}=120,66 \%$ ) were admitted to the critical care unit, where their blood pressure was monitored and adjusted by optimal medical therapy (systolic arterial pressure $<120 \mathrm{~mm} \mathrm{Hg}$ ) including a tailored antihypertensive regimen. Patients were switched to oral administration as soon as possible and closely observed for evidence of extremity, visceral, or renal malperfusion. Pain was treated according to World Health Organization guidelines. After discharge, the patients continued to receive oral antihypertensive therapy. CTA was performed at the time of diagnosis and repeated before discharge or in the case of complications. During follow-up, control computed tomography scans were performed after 3, 6 , and 12 months and thereafter annually. The CTA data were analyzed by 2 independent investigators with regard to the maximum axial diameter of the aorta, extension of the dissection, and patency or thrombosis of the true lumen and the side branches. Among the patients who received initial medical treatment, 16 were lost to follow-up. This retrospective data analysis was performed according to our local ethics committee, and the data of 104 patients, including comorbidity and morphologic data, were reviewed.

\footnotetext{
Statistical Analysis

Continuous variables are expressed as mean values \pm standard deviation or median and interquartile range (IQR). This article constitutes 2 time-toevent end points. The first time-to-event end point is "death," reflecting a classic survival setting. In addition, the time-to-event end point "treatment failure" was investigated. Treatment failure was defined as death or surgery after conservative treatment. Both end points were analyzed descriptively using Kaplan-Meier estimates, illustrated by the corresponding curves in Figures 1 and 2, and inferentially by univariate and multivariate Cox regression analysis. First, univariate Cox regression analysis was performed to investigate the influence of diameter ( $\geq 41 \mathrm{vs}<41 \mathrm{~mm}$ ) on
}

both end points. Multivariate analysis was then performed to investigate the influence of diameter, age, gender, and, in case of survival, surgery. For the latter, after establishing a high-risk category (aortic diameter $\geq 41 \mathrm{~mm}$ and age $\geq 66$ years), multivariate Cox regression analysis was performed to investigate the influence of this factor, gender, and surgery on survival. In all multivariate Cox regressions on survival, surgery was modeled as a time-dependent risk factor because of its change over time for a subset of the study cohort. The significance level was set at $\alpha=0.05$. All Cox regression analyses were performed using SAS version 9.2 (SAS Institute Inc, Cary, NC). Kaplan-Meier estimates and graphs were created using R ( $\mathrm{R}$ Version 2.11.1, 2010, The R Foundation for Statistical Computing).

\section{RESULTS \\ Patient Characteristics}

In the 120 patients with a mean age of $65.98 \pm 11.2$ years (range, 29-87 years) included in the database, the onset of symptoms was clearly assessable within the 14 days preceding admission and typical of aortic dissection. Diagnosis was established on the basis of computed tomography within 14 days of the onset of pain. At the time of the initial diagnosis, all patients were considered for medical treatment. Sixteen of these 120 patients were lost during follow-up. The study group included 74 men $(70.8 \%)$ and 30 women $(29.2 \%)$, and the comorbidities were diabetes in 7 of 104 patients, hypertension in 90 of 104 patients, coronary artery disease in 30 of 104 patients, renal insufficiency in 15 of 104 patients, smoking in 33 of 104 patients, and connective tissue disease in 3 of 104 patients. Three patients had an acute dissection superimposed on chronic aneurysms.

\section{Conversion to Invasive Therapy}

During the follow-up period, the initial medical treatment was converted to surgical treatment in 21 patients $(20.2 \%)$ after a median of 333 days (IQR, 578 days; lower [25\%] quartile value, 125 days; upper [ $75 \%$ ] quartile value, 703 days; range, $1-1656$ days) (mean, $488.7 \pm 514.4$ days). In 5 patients $(4.8 \%)$, endovascular surgery was performed during the acute dissection phase (within 14 days) because of acute complications, despite the best medical treatment. Reasons for TEVAR were rapid extension of the transversal aortic diameter within 14 days $(n=2 ; 1$ man aged 58 years, 1 woman aged 57 years), aortic rupture after 5 and 9 days $(\mathrm{n}=2$ men aged 78 and 63 years), and renal ischemia ( $\mathrm{n}=1$ man aged 67 years). One of these 5 patients, a 63-year-old man, died of aortic rupture and subsequent hemodynamic shock 5 days after TEVAR.

In 16 patients $(15.4 \%$; 10 women), surgery was performed after a median of 189 days (IQR, 535.5 days; lower [25\%] quartile value, 105.5 days; upper [75\%] quartile value, 641 days; range, 1-1586 days) (mean, $631.8 \pm 499.4$ days). Surgical treatment was indicated because of aortic enlargement $(n=14)$, rupture $(n=1)$, or lower-limb ischemia $(\mathrm{n}=1)$ (Table E1). Surgery 

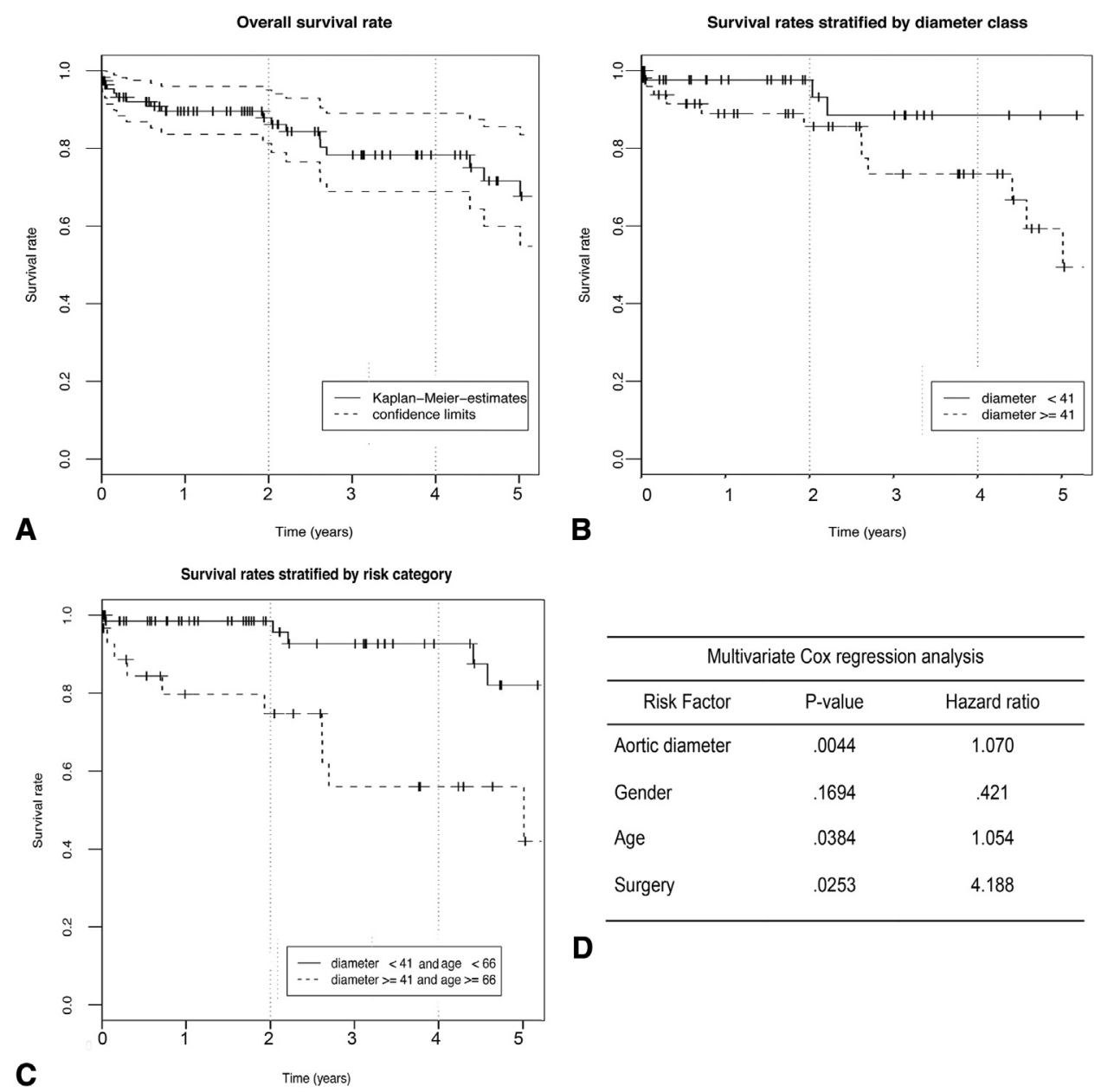

\begin{tabular}{lcc}
\hline \multicolumn{3}{c}{ Multivariate Cox regression analysis } \\
\hline \multicolumn{1}{c}{ Risk Factor } & P-value & Hazard ratio \\
\hline Aortic diameter & .0044 & 1.070 \\
Gender & .1694 & .421 \\
Age & .0384 & 1.054 \\
Surgery & .0253 & 4.188 \\
\hline
\end{tabular}

D

FIGURE 1. Survival. A, Cumulative all-cause survival. B, Univariate analysis revealed a significant difference in the cumulative survival between patients with an aortic diameter $\geq 41 \mathrm{~mm}$ and patients with an aortic diameter $<41 \mathrm{~mm}(P=.012)$. Kaplan-Meier estimates are presented in Table 1. C, Survival stratified by diameter and age. D, Multivariate Cox regression analysis.

included TEVAR $(\mathrm{n}=2)$, endovascular aortic repair $(n=1)$, open repair of the infrarenal aorta $(n=2)$, Crawford type I repair $(n=2)$, type II repair $(n=6)$, type III repair $(\mathrm{n}=1)$, and hybrid procedures $(\mathrm{n}=2)$.

\section{Diameter of Dissection}

The mean maximum aortic transverse diameter on admission was $41.2 \pm 8.7 \mathrm{~mm}$. Two patient groups were created using the median of $41 \mathrm{~mm}$ as a cutoff, resulting in a group with a diameter less than $41 \mathrm{~mm}(\mathrm{n}=51)$ and a group with a diameter of $41 \mathrm{~mm}$ or more $(\mathrm{n}=53)$.

\section{Mortality}

Sixteen patients $(15.4 \%)$ died after a median of 774 days (IQR, 1252 days; lower [25\%] quartile value, 38.5 days; upper [75\%] quartile value, 1291 days; range, 2-2805 days) (mean, $826.6 \pm 819.1$ days). Two patients (both men) died of aortic rupture during the acute phase of dissection, despite the best medical treatment. One of these patients (aged 80 years) died 2 days after the dissection event. The other patient was aged 63 years; he sustained an aortic rupture 9 days after the initial dissection and was referred for emergency TEVAR. Five days after TEVAR, the patient died as a consequence of hemodynamic shock as noted earlier. Of the 14 patients who died during the chronic phase of dissection, 2 died of causes that were not dissection related. In 6 patients, the cause of death remains unknown. Therefore, a total of 6 patients died of dissection-related causes (rupture $\mathrm{n}=4$; intestinal ischemia $\mathrm{n}=1$; rupture after TEVAR $=1$ ).

The cumulative all-cause survival at 1,3 , and 6 years was $89.6 \%( \pm 3.2), \quad 78.3 \% \quad( \pm 5.1), \quad$ and $67.7 \% \quad( \pm 7.3)$, respectively (Figure $1, A$ ). Univariate analysis revealed a significant difference in the cumulative survival between the 2 diameter groups $(P=.012$, Figure $1, B$ and Table 1) with a hazard ratio (HR) of 4.44 for a diameter of $41 \mathrm{~mm}$ or greater. The multivariate analysis identified aortic diameter $(P=.004 ; \mathrm{HR}, 1.07)$ and age $(P=.038 ; \mathrm{HR}, 1.05)$ as 


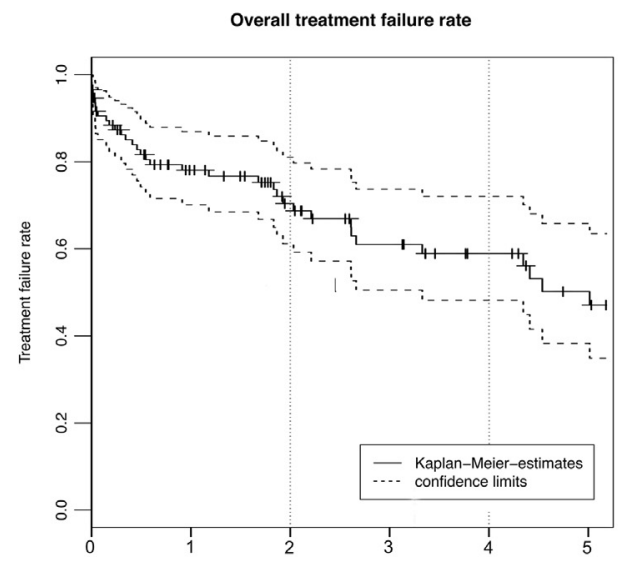

A Time (years)

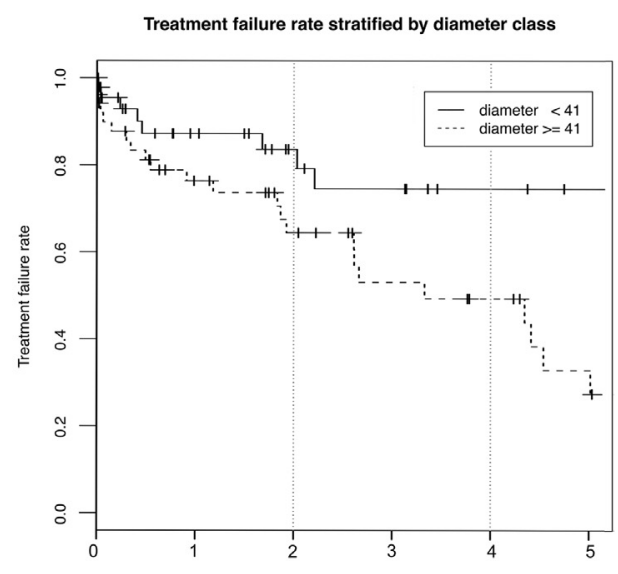

B

Time (years)

FIGURE 2. Treatment failure. A, Overall failure of conservative treatment. B, Failure of treatment stratified by diameter class revealed a significantly higher rate in patients with an aortic diameter $\geq 41 \mathrm{~mm}(P=.09$; HR, 2.93). Kaplan-Meier estimates are presented in Table 2.

risk factors that significantly reduce survival (Figure $1, D$ ). However, the age distribution between the 2 patient cohorts based on diameter was unequal, with older patients more likely to have a diameter of $41 \mathrm{~mm}$ or more. After correcting the binary risk factor, the HR for a diameter of $41 \mathrm{~mm}$ or more was 3.36 and not significant $(P=.071)$. Another risk factor influencing survival was surgical treatment during the follow-up (Figure 1, D). Identification of diameter and age as risk factors motivated the formation of a high-risk patient cohort characterized by an aortic diameter of $41 \mathrm{~mm}$ or more and age 66 years or more. The cutoff level for age was set at the median of overall

TABLE 1. Mortality Kaplan-Meier estimates stratified by diameter group

\begin{tabular}{|c|c|c|c|c|c|}
\hline \multicolumn{6}{|c|}{ Mortality stratified by diameter group } \\
\hline Time (d) & No. at risk & Survival & $\begin{array}{l}\text { Standard } \\
\text { error }\end{array}$ & $\begin{array}{c}\text { Lower } \\
95 \% \text { CI }\end{array}$ & $\begin{array}{c}\text { Upper } \\
95 \% \text { CI }\end{array}$ \\
\hline \multicolumn{6}{|c|}{ Diameter $<41 \mathrm{~mm}$} \\
\hline 14 & 42 & 0.976 & 0.0235 & 0.931 & 1.000 \\
\hline 742 & 22 & 0.932 & 0.0488 & 0.841 & 1.000 \\
\hline 807 & 20 & 0.885 & 0.0649 & 0.767 & 1.000 \\
\hline \multicolumn{6}{|c|}{ Diameter $\geq 41 \mathrm{~mm}$} \\
\hline 2 & 53 & 0.981 & 0.0187 & 0.9452 & 1.000 \\
\hline 23 & 45 & 0.959 & 0.0283 & 0.9055 & 1.000 \\
\hline 54 & 44 & 0.938 & 0.0350 & 0.8713 & 1.000 \\
\hline 109 & 41 & 0.915 & 0.0410 & 0.8378 & 0.999 \\
\hline 261 & 36 & 0.889 & 0.0471 & 0.8017 & 0.986 \\
\hline 705 & 27 & 0.856 & 0.0557 & 0.7539 & 0.973 \\
\hline 954 & 21 & 0.816 & 0.0663 & 0.6954 & 0.956 \\
\hline 956 & 20 & 0.775 & 0.0745 & 0.6417 & 0.935 \\
\hline 984 & 19 & 0.734 & 0.0809 & 0.5913 & 0.911 \\
\hline 1610 & 11 & 0.667 & 0.0973 & 0.5014 & 0.888 \\
\hline 1672 & 9 & 0.593 & 0.1112 & 0.4108 & 0.856 \\
\hline 1830 & 6 & 0.494 & 0.1293 & 0.2960 & 0.825 \\
\hline 2805 & 2 & 0.247 & 0.1863 & 0.0564 & 1.000 \\
\hline
\end{tabular}

CI, Confidence interval. age values (65.98 years). In regard to death, multivariate Cox regression analysis revealed a significant $(P=.0004)$ HR of 6.87. Figure 1, $C$ illustrates the difference in regard to cumulative survival between the high-risk patient cohort (group aortic diameter $\geq 41 \mathrm{~mm}$ and age $\geq 66$ years) and the remaining patients (age $<66$ years or aortic diameter $<41 \mathrm{~mm}$ ) (Figure 1, C).

\section{Treatment Failure}

After analysis of death and conversion to invasive treatment separately, we combined these 2 end points and addressed treatment failure of conservative treatment. A total of 32 patients had treatment failure due to death or conversion to invasive therapy after a median of 382 days (IQR, 883.5 days; lower [25\%] quartile value, 70 days; upper [75\%] quartile value, 953.5 days; range, 0-2805 days) (mean, $615.4 \pm 686.9$ days). Similar to the analysis of mortality, univariate analysis of the aortic diameter displayed a significant higher rate of treatment failure for patients with a larger aortic diameter $(P=.11$; HR, 1.038). In the diameter groups, an aortic diameter of $41 \mathrm{~mm}$ or more led to a significantly higher rate of treatment failure ( $P=.009$; HR, 2.93) (Figure 2 and Table 2). Univariate analysis of gender and older age revealed no significant influence (gender: $P=.116$; HR, 0.56; older age: $P=.92$; HR, 1.00). The multivariate analysis, including diameter, gender, and older age, identified female gender $(P=.047$; HR, 2.131) and diameter ( $P=.004 ; \mathrm{HR}, 1.05)$, but not older age $(P=.662 ; \mathrm{HR}, 0.992)$, as risk factors of treatment failure. However, the high-risk group (group aortic diameter $\geq 41 \mathrm{~mm}$ and age $\geq 66$ years) showed no significant difference regarding treatment failure.

\section{DISCUSSION}

This study followed 104 patients with initial uncomplicated type B dissections and identified a patient group with 
TABLE 2. Treatment failure Kaplan-Meier estimates stratified by diameter group

\begin{tabular}{|c|c|c|c|c|c|}
\hline \multicolumn{6}{|c|}{ Treatment failure stratified by diameter group } \\
\hline Time (d) & No. at risk & Survival & $\begin{array}{c}\text { Standard } \\
\text { error }\end{array}$ & $\begin{array}{c}\text { Lower } \\
\mathbf{9 5} \% \text { CI } \\
\end{array}$ & $\begin{array}{c}\text { Upper } \\
95 \% \text { CI } \\
\end{array}$ \\
\hline \multicolumn{6}{|c|}{ Diameter $<41 \mathrm{~mm}$} \\
\hline 5 & 46 & 0.978 & 0.0215 & 0.937 & 1.000 \\
\hline 14 & 41 & 0.954 & 0.0316 & 0.895 & 1.00 \\
\hline 86 & 37 & 0.929 & 0.0399 & 0.854 & 1.000 \\
\hline 150 & 33 & 0.900 & 0.0476 & 0.812 & 0.999 \\
\hline 167 & 32 & 0.872 & 0.0538 & 0.773 & 0.984 \\
\hline 613 & 24 & 0.836 & 0.0626 & 0.722 & 0.968 \\
\hline 742 & 19 & 0.792 & 0.0732 & 0.661 & 0.949 \\
\hline 807 & 17 & 0.745 & 0.0824 & 0.600 & 0.926 \\
\hline \multicolumn{6}{|c|}{ Diameter $\geq 41 \mathrm{~mm}$} \\
\hline 1 & 52 & 0.981 & 0.0190 & 0.9441 & 1.000 \\
\hline 2 & 51 & 0.962 & 0.0267 & 0.9107 & 1.000 \\
\hline 5 & 48 & 0.942 & 0.0328 & 0.8794 & 1.000 \\
\hline 13 & 44 & 0.920 & 0.0384 & 0.8479 & 0.999 \\
\hline 23 & 43 & 0.899 & 0.0431 & 0.8182 & 0.987 \\
\hline 54 & 42 & 0.877 & 0.0470 & 0.7898 & 0.975 \\
\hline 109 & 40 & 0.855 & 0.0507 & 0.7615 & 0.961 \\
\hline 125 & 39 & 0.833 & 0.0540 & 0.7341 & 0.946 \\
\hline 180 & 38 & 0.812 & 0.0568 & 0.7075 & 0.931 \\
\hline 199 & 35 & 0.788 & 0.0597 & 0.6795 & 0.915 \\
\hline 333 & 32 & 0.764 & 0.0627 & 0.6501 & 0.897 \\
\hline 431 & 28 & 0.736 & 0.0662 & 0.6175 & 0.878 \\
\hline 669 & 24 & 0.706 & 0.0702 & 0.5808 & 0.858 \\
\hline 681 & 23 & 0.675 & 0.0735 & 0.5453 & 0.836 \\
\hline 703 & 22 & 0.644 & 0.0763 & 0.5109 & 0.813 \\
\hline 953 & 17 & 0.606 & 0.0807 & 0.4673 & 0.787 \\
\hline 954 & 16 & 0.569 & 0.0841 & 0.4255 & 0.760 \\
\hline 972 & 15 & 0.531 & 0.0866 & 0.3854 & 0.731 \\
\hline 1215 & 14 & 0.493 & 0.0883 & 0.3468 & 0.700 \\
\hline 1586 & 9 & 0.438 & 0.0940 & 0.2877 & 0.667 \\
\hline 1610 & 8 & 0.383 & 0.0969 & 0.2335 & 0.629 \\
\hline 1656 & 7 & 0.329 & 0.0973 & 0.1839 & 0.587 \\
\hline 1830 & 6 & 0.274 & 0.0952 & 0.1384 & 0.541 \\
\hline 2805 & 2 & 0.137 & 0.1079 & 0.0292 & 0.641 \\
\hline
\end{tabular}

significantly increased mortality. Patients aged more than 66 years with a maximum aortic diameter greater than $40 \mathrm{~mm}$ at admission had a 6.87-fold higher mortality risk than younger patients and patients with smaller aortic diameters. Our findings are in agreement with Onitsuka and colleagues, ${ }^{16}$ who examined the long-term outcome and prognostic predictors related to the development of complications associated with acute type B aortic dissection in 66 medically treated patients. A substantial difference was found in the initial maximum aortic diameter in patients with dissection-associated complications and patients with no complications.

Older patients generally take on a higher surgical risk than younger patients. Thus, if surgical procedures are required because of complications during the chronic course of a dissection, age seems to be a significant predictive risk factor. In their risk prediction model based on IRAD data, Suzuki and colleagues ${ }^{17}$ identified hypotension/shock, absence of chest/back pain, and branch vessel involvement, but not age ( $\geq 70$ years), as independent predictors of in-hospital death. Furthermore, age 70 years or more was not an independent predictor of death during long-term follow-up in another published analysis of IRAD data. ${ }^{6}$ In contrast to the IRAD studies, the present analysis included age as a continuous variable, allowing more information and identifying it as an independent predictor of death. Data in the present study suggest that older patients take advantage of more aggressive therapy in the initial treatment of uncomplicated dissections to prevent conditions that necessitated later chronic phase surgery.

Multivariate analysis showed that later conversion to an invasive treatment significantly influenced survival. However, the study design does not allow a valid comparison between the groups in regard to invasive treatment. The need for surgical or endovascular treatment of an initially uncomplicated type B dissection is always an indicator of dissection-associated complications. Thus, extremely ill patients underwent operations. Moreover, invasive therapy carries an inherent risk of mortality, particularly in older patients; therefore, these patients have a greater risk compared with patients who do not require surgery during the course of dissection. Thus, influencing the course of dissection therapeutically is important to avoid the development of conditions that necessitate late surgical treatment. Aortic expansion was the most common complication leading to surgery in this study.

Because of morphologic conditions, endovascular or hybrid treatment was possible in only 6 of the 17 patients. Despite measures including cerebrospinal fluid drainage, distal and selective organ perfusion, and monitoring of motor evoked potentials, open surgery of extensive type B dissections causes serious surgical trauma and is associated with a high mortality. ${ }^{18-20}$

Furthermore, we combined mortality and conversion with invasive therapy and addressed treatment failure of conservative treatment of type $\mathrm{B}$ dissection. Although aortic diameter remained a risk factor, older age was not a significant risk factor in this analysis. However, the multivariate analysis revealed female gender as another risk factor for treatment failure of conservative treatment.

However, the absolute benefit of TEVAR over alternative treatments for chronic type B dissections remains unclear. ${ }^{21}$ In the case of acute dissection, several studies have shown the potential of TEVAR in remodeling acute dissected descending aortic walls. ${ }^{22-24}$ Furthermore, the INSTEAD trial confirmed that aortic remodeling due to TEVAR 
effectively results in significant aneurysm shrinkage after 2 years compared with medicamentously treated patients, but this effect had no significant influence on the survival in the TEVAR group. The 2-year cumulative all-cause survival of conservatively treated patients in the INSTEAD trial was $88.9 \%$ and comparable to our estimate of $87.9 \%$ in the present report. ${ }^{2}$ In contrast to these results after 2 years, the results after 5 years revealed a reduction of mortality by TEVAR, ${ }^{25}$ which may indicate a promising role of TEVAR in uncomplicated type B dissection.

\section{CONCLUSIONS}

In regard to mortality, the main finding of our study was the identification of a subgroup of patients at high risk (aortic diameter $\geq 41 \mathrm{~mm}$ and age $\geq 66$ years), who had a 2-year survival of only $68.5 \%$. In contrast, patients who did not fulfill the high-risk criteria displayed a cumulative survival of $95.7 \%$ after 2 years. Nevertheless, because of the retrospective, nonrandomized design of this report, conclusions from this multicenter analysis have to be drawn cautiously. Uncomplicated type B dissections in patients aged 66 years or more with a maximum aortic diameter greater than $41 \mathrm{~mm}$ on admission seem to present a higher risk of mortality. However, further studies are needed to determine with more certainty whether patients with uncomplicated type B dissections benefit from prophylactic TEVAR, particularly in older patients and in cases of early aortic dilatation.

\section{References}

1. Hiratzka LF, Bakris GL, Beckman JA, Bersin RM, Carr VF, Casey DE Jr, et al. 2010 ACCF/AHA/AATS/ACR/ASA/SCA/SCAI/SIR/STS/SVM Guidelines for the diagnosis and management of patients with thoracic aortic disease. A Report of the American College of Cardiology Foundation/American Heart Association Task Force on Practice Guidelines, American Association for Thoracic Surgery, American College of Radiology, American Stroke Association, Society of Cardiovascular Anesthesiologists, Society for Cardiovascular Angiography and Interventions, Society of Interventional Radiology, Society of Thoracic Surgeons, and Society for Vascular Medicine. J Am Coll Cardiol. 2010;55: e27-129.

2. Nienaber CA, Rousseau H, Eggebrecht H, Kische S, Fattori R, Rehders TC, et al. Randomized comparison of strategies for type B aortic dissection: the INvestigation of STEnt Grafts in Aortic Dissection (INSTEAD) trial. Circulation. 2009; 120:2519-28.

3. Bernard Y, Zimmermann H, Chocron S, Litzler JF, Kastler B, Etievent JP, et al. False lumen patency as a predictor of late outcome in aortic dissection. Am J Cardiol. 2001;87:1378-82.

4. Elefteriades JA. Natural history of thoracic aortic aneurysms: indications for surgery, and surgical versus nonsurgical risks. Ann Thorac Surg. 2002;74: S1877-80.

5. Gysi J, Schaffner T, Mohacsi P, Aeschbacher B, Althaus U, Carrel T. Early and late outcome of operated and non-operated acute dissection of the descending aorta. Eur J Cardiothorac Surg. 1997;11:1163-70.
6. Tsai TT, Fattori R, Trimarchi S, Isselbacher E, Myrmel T, Evangelista A, et al. Long-term survival in patients presenting with type B acute aortic dissection: insights from the International Registry of Acute Aortic Dissection. Circulation. 2006;114:2226-31.

7. Umana JP, Lai DT, Mitchell RS, Moore KA, Rodriguez F, Robbins RC, et al. Is medical therapy still the optimal treatment strategy for patients with acute type B aortic dissections? J Thorac Cardiovasc Surg. 2002;124:896-910.

8. Jonker FH, Trimarchi S, Muhs BE, Rampoldi V, Montgomery DG, Froehlich JB, et al. The role of age in complicated acute type B aortic dissection. Ann Thorac Surg. 2013;96:2129-34.

9. Mehta RH, Bossone E, Evangelista A, O'Gara PT, Smith DE, Cooper JV, et al. Acute type B aortic dissection in elderly patients: clinical features, outcomes, and simple risk stratification rule. Ann Thorac Surg. 2004;77:1622-9.

10. Estrera AL, Miller CC III, Safi HJ, Goodrick JS, Keyhani A, Porat EE, et al. Outcomes of medical management of acute type B aortic dissection. Circulation. 2006;114:I384-9.

11. Hughes GC, Andersen ND, McCann RL. Management of acute type B aortic dissection. J Thorac Cardiovasc Surg. 2013;145:S202-7.

12. Ehrlich MP, Rousseau H, Heijmen R, Piquet P, Beregi JP, Nienaber CA, et al. Midterm results after endovascular treatment of acute, complicated type B aortic dissection: the Talent Thoracic Registry. J Thorac Cardiovasc Surg. 2013;145: 159-65.

13. Bossone E, Pyeritz RE, O'Gara P, Harris KM, Braverman AC, Pape L, et al. Acute aortic dissection in blacks: insights from the international registry of acute aortic dissection. Am J Med. 2013;126:909-15.

14. Svensson LG, Kouchoukos NT, Miller DC, Bavaria JE, Coselli JS, Curi MA, et al. Expert consensus document on the treatment of descending thoracic aortic disease using endovascular stent-grafts. Ann Thorac Surg. 2008;85:S1-41.

15. Elefteriades JA, Lovoulos CJ, Coady MA, Tellides G, Kopf GS, Rizzo JA Management of descending aortic dissection. Ann Thorac Surg. 1999;67: 2002-5; discussion 2014-9.

16. Onitsuka S, Akashi H, Tayama K, Okazaki T, Ishihara K, Hiromatsu S, et al. Long-term outcome and prognostic predictors of medically treated acute type B aortic dissections. Ann Thorac Surg. 2004;78:1268-73.

17. Suzuki T, Mehta RH, Ince H, Nagai R, Sakomura Y, Weber F, et al. Clinical profiles and outcomes of acute type B aortic dissection in the current era: lessons from the International Registry of Aortic Dissection (IRAD). Circulation. 2003;108(Suppl 1):II312-7.

18. Jacobs MJ, Mommertz G, Koeppel TA, Langer S, Nijenhuis RJ, Mess WH, et al. Surgical repair of thoracoabdominal aortic aneurysms. J Cardiovasc Surg (Torino). 2007:48:49-58.

19. Mommertz G, Langer S, Koeppel TA, Schurink GW, Mess WH, Jacobs MJ. Brain and spinal cord protection during simultaneous aortic arch and thoracoabdominal aneurysm repair. J Vasc Surg. 2009;49:886-92.

20. Coselli JS, Bozinovski J, LeMaire SA. Open surgical repair of 2286 thoracoabdominal aortic aneurysms. Ann Thorac Surg. 2007;83:S862-4.

21. Thrumurthy SG, Karthikesalingam A, Patterson BO, Holt PJ, Hinchliffe RJ, Loftus IM, et al. A systematic review of mid-term outcomes of thoracic endovascular repair (TEVAR) of chronic type B aortic dissection. Eur J Vasc Endovasc Surg. 2011;42:632-47.

22. O'Donnell S, Geotchues A, Beavers F, Akbari C, Lowery R, Elmassry S, et al Endovascular management of acute aortic dissections. J Vasc Surg. 2011;54 $1283-9$.

23. Duebener LF, Lorenzen P, Richardt G, Misfeld M, Notzold A, Hartmann F, et al. Emergency endovascular stent-grafting for life-threatening acute type B aortic dissections. Ann Thorac Surg. 2004;78:1261-7.

24. Rodriguez JA, Olsen DM, Lucas L, Wheatley G, Ramaiah V, Diethrich EB Aortic remodeling after endografting of thoracoabdominal aortic dissection. J Vasc Surg. 2008;47:1188-94.

25. Nienaber CA, Kische S, Rousseau H, Eggebrecht H, Rehders TC, Kundt G, et al Endovascular repair of type $\mathrm{B}$ aortic dissection: long-term results of the Randomized Investigation of Stent Grafts in Aortic Dissection Trial. Circ Cardiovasc Interv. 2013;6:407-16. 
TABLE E1. Timing of intervention

\begin{tabular}{lcl}
\hline Cases & $\begin{array}{c}\text { Timing of } \\
\text { intervention (d) }\end{array}$ & \multicolumn{1}{c}{ Kind of intervention } \\
\hline 1 & 125 & Type II repair \\
2 & 150 & TEVAR with carotid subclavian bypass \\
3 & 167 & Femoro-femoral bypass \\
4 & 180 & EVAR with crossover bypass \\
5 & 199 & Type I repair \\
6 & 207 & TEVAR \\
7 & 261 & TEVAR \\
8 & 431 & Type I repair \\
9 & 613 & TEVAR with carotid subclavian bypass \\
10 & 669 & Type II repair \\
11 & 703 & Type II repair \\
12 & 956 & Type III repair \\
13 & 984 & Type II repair \\
14 & 1215 & AAA repair \\
15 & 1586 & AAA repair \\
16 & 1656 & Type II repair \\
\hline$A A A$, Abdominal aortic aneurysm; & EVAR, endovascular aneurysm repair; TEVAR, \\
thoracic endovascular aneurysm repair.
\end{tabular}

